2018 Global Marketing Conference at Tokyo Proceedings: 444-449 (July 2018) https://doi.org/10.15444/GMC2018.04.03.03

\title{
COGNITIVE COMPUTING AND DYNAMIC MARKETING TO PERSONALIZE FOR THE NEXT GENERATION OF LUXURY SWISS WATCH CUSTOMERS
}

\author{
Wendy K. Bendoni, Woodbury University, School of Business, USA \\ Maria Bashutkina, HEG Arc, HES SO University of Applied Sciences Western \\ Switzerland, Switzerland ${ }^{1}$
}

\section{FULL PAPER}

\section{Introduction}

This research will investigate the advancement of cognitive computing and how it can be applied through 'Dynamic Marketing Capabilities' (Bruni and Verona, 2009) to raise the bar of personalizing services and amenities provided to the luxury watch market loyal customer. Through intuitive digital applications, new levels of interactive systems can focus on explicitly the next generation of hyper-connected luxury customers.

\section{Theoretical Development}

The purpose of this research is to investigate how to personalize the communication process in the luxury market segment through cognitive computing and address the high expectation of the new affluent consumer of the digital age. The next generation of affluent luxury consumers is accustomed to interactive systems and personalized interfaces that enable computers to get more intuitive of the customer(s) to enable them to personal the individual's needs. This level of personalization undoubtedly raises the bar on the luxury customer's journey from the tactile in-person luxury shopping experience currently found in brick-and-mortar locations, to a decidedly more interactive and increasingly immersive online customer experience. Abbott (1955) and Alderson (1957) focused on the notion that "what people desire are not products but satisfying experiences" (Abbot 1955, p. 40). The fundamentals of cognitive computing are to recognizing trends and behaviors that enable companies to utilize Artificial Intelligence to make proper predictions and give insight to intuitively give consumers what they need before they have to request it. The idea behind this research is to take the traditional luxury market sector of Swiss watches and combine it with the intuitive software provided by cognitive computing.

\section{Research Design}

According to the Federation of the Swiss Watch Industry (FHS) in 2017, Switzerland occupies only $3 \%$ of the global market regarding the quantity of watches. As for value, Switzerland represents $54 \%$ of global sales that is 21 billion USD. Thus, about $95 \%$ of luxury watches with price starting from 1,000 USD are stamped "Swiss Made." Thus, the Swiss watch industry has become an integral part of the luxury universe. However, it's not an easy task to get a place in this luxury market of reference. According to the estimation made by the Institute of Watch Marketing, there are approximately 200 active Swiss independent watch brands on the market today. Under conditions of the highly competitive market, the challenge concerns not only

\footnotetext{
${ }^{1}$ Maria.Bashutkina@he-arc.ch
} 
market share, but also competitive advantage as well as customer relationships or brand equity.

We situate this research within the context of the Swiss luxury watchmaking industry and focus on the power of the website to increase customer loyalty. We suggest ways to utilize a brand's electronic (desk, mobile, tablet) touch points to aggregate data to gain a deeper understanding of their loyalist. Armed with knowledge, luxury watch brands can connect to their customers through the power of artificial intelligence. Affluent "digital native" consumers have "hyper-connected" instincts, and increasingly expect more from their chosen brands through next-level personalization. The continued evolution of consumers' online behavior, attitude, and expectations from brands currently exceeds what is possible for a single human to process. It is, therefore, becoming increasingly necessary to incorporate both the power of cognitive computing and the information gleaned from large data sets (big data) to produce more intuitive and personalized experiences. This information enhances the brand's ability to uncover behavioral patterns and begin to incorporate "machine learning," (a subset of AI) a calculated algorithm that can facilitate the process of personalization. The speed at which data can now be processed, analyzed, clustered and contextualized has increased the value of machine learning in the world of the consumer experience.

Personalization of luxury branded communication that utilize artificial intelligence (AI) to help them connect intuitively with their audience are more apt to meet the needs of the next generation of affluent consumers on a more personalized level. By focusing on the shift in adaptive interactive systems, we highlight the power of cognitive computing to help offer more intuitive luxury personalization for their loyal customers (owners of the brand's watches). Achieving this stage of customization requires computers to mimic human intelligence using logic and insight. This research will explore new opportunities to help identify the independent luxury watch industry to capture the attention of the next generation of customers in cyber-space.

The customer's journey no longer ends at the front door of the traditional brick-andmortar location - it continues into the digital space and even starts from it. Offline Swiss luxury watch brands have mastered the role of personalization through "white glove" in-person customer service and installations exhibiting their expert craftsmanship. This level of customer service is still best accomplished through cultivating and curating the boutique shopping experience, although AI is rapidly changing this dynamic. Currently, the online experiences of luxury watch brands have proven to be less than satisfying for their discriminating clientele because most still shy away from creating a fully-realized digital landscape including an e-commerce presence. Independent watch brands need to push beyond the generic expectations and curate rich aesthetic experiences that set a crucial dimension of the luxury sector (Berthon et al. 2009). This research begins to address how Swiss luxury watch brands can fully embrace the digital evolution and strategically utilize the valued subset of AI including cognitive computing, machine learning, and adaptive interactive systems. AI machine learning will ensure the level of personalization to which the discerning luxury customer has grown accustomed. The next section details how watchmakers can accomplish this integration.

\section{Conceptual Framework}


Over the past years, researchers have increased conceptual understanding of the role of marketing in enabling firms to create and sustain competitive advantage and superior value (Ramaswami et al., 2009). By potential to improve business performance, some studies (Bruni and Verona, 2009), have introduced the term 'Dynamic Marketing Capabilities' (DMCs hereafter).

In fact, DMCs are focused explicitly on releasing and integrating the market knowledge that helps firms evolve. The strategic position of marketing to absorb market knowledge allows Swiss luxury watch brands to provide accurate insight into brand equity and distinctive experience. DMCs are capabilities that use market knowledge to adapt firms' resources and capabilities (Day, 1994; Slater and Naver, 1998).

In this research will explore the characteristics and uses of market-based resources, such as building brands, relationships, and knowledge and apply to digital solutions through interactive systems and personalized interfaces. This market-based perspective suggests that marketing research increasingly focuses on intangible, complementary resources, whose effects on the firm's sustained competitive advantage (SCA) and performance may be greater than the impact of tangible resources (Srivastava et al.1998). As much as 70\% of a firm's market value may come from its intangible resources (Capraro and Srivastava 1997), and organizational performance increasingly seems tied to intangible resources, such as customer relationships or brand equity (Lusch and Harvey 1994).

The abundance of active users globally on the internet, smartphones, laptops, tablets, and desktops creates a wealth of data, up to 80 percent of which is untapped and unstructured and not contextualized for use (Alexander, 2016). This unused data often referred to as "dark data," includes web images, social media networks, emails, blogs, and videos (Alexander, 2016). An analysis of the online behavior of a brand's current customers contributes to the formation of stronger, more meaningful clusters based on current customer personas to reveal patterns of similar interests between groups of customers. This majority of available data can be analyzed by machine learning, and "the more data an algorithm can train on, the more accurate it will be" (Deep Learning, $\mathrm{n} / \mathrm{a}$ ). The sub-domain of machine learning, deep learning, which is itself a sub-domain of AI, breaks down tasks to make machine assistance possible (Copeland, 2016). Thus, deep learning provides insights, which can then be used to help curate a personalized experience through predictive analytics.

Gathering customer attributes through insight for this research requires that we take a closer look at similar customer gathering registering their watches online (serial number required) making sure to capture necessary demographic and psychographic information, and through using clientele retail locations, which would then was mined for insights and more branded content. The reactive software would utilize deep learning algorithms to recognize moments, behavior and geo-location to offer realtime personalized mobile engagement.

The increasingly common practice of merging of marketing teams enhances marketing deliverables through the User Interface (UI) and User Experience (UX). The interface, coupled with the experience, need to work synergistically to drive 
curiosity and encourage the user to explore and discover what will eventually become more personally-targeted curated content on the website.

To further explain how these technologies can be employed for the luxury watchmaking companies, we examine several Swiss luxury watch brands. Describing how actionable data derived from cognitive computing can create a more intuitive customer experience, Vishal Katelia, Senior Manager, Global CRM at the luxury ecommerce website Mr. Porter provides an analogy from the luxury hotel world. He says that luxury hotels excel in many ways, "especially around the 'surprise and delight' aspect of keeping track of small but important details that personalize their clientele's experience from the type of pillow they prefer to sleep on. Paying attention to these details can ensure future expertise, are as perfect as the hotel can offer (Miller, 2016).

While machine learning focuses on building machines that replicate the human brain's cognitive capabilities to apply this knowledge from cognitive science to react in a intuitive way (Jones, 2017). Artificial intelligence refers to "a broad set of methods, algorithms and technologies that make software 'smart' in a way that may seem human-like to an outside observer," according to Lynne Parker, director of the division of Information and Intelligent Systems for the National Science Foundation (Noyes, K., 2016). Cognitive technologies are themselves products of artificial intelligence that perform human-like tasks such as speech recognition, natural language process, machine learning, computer vision (Schatsky D., Muraskin, Ragu Gurumurthy, R. 2015). Furthermore, it is important to look beyond AI to the most efficient way to personalize the customer's experience. By using cognitive technologies marketers can create intuitive experiences for customers offering services and experiences based on behavioral profiling through data clusters and affinity analysis.

\section{Result}

The actionable insight that can be gained through this research was presented in a two-pronged process. First, connecting data that would typically be collected from a brand' e-commerce customers' journey now would be used to produce more curated content. The ability to apply cognitive computing through tools such as Qubit (data science company) that was used for this study that offers gives us the opportunity to apply an affinity analysis to form insights, patterns, behaviors that previously were undiscovered. Insights gathered would help to identify and reward loyal customers beyond the standard loyalty programs with notifications, private activations on geolocation services. Second, understanding the UX and UI on the websites of the three pre-selected independent luxury watch brands enabled us to follow and eventually understand the user's journey both on mobile and desktop. The personalization of the interface allows for in-depth learning to better understand an individual's needs and create an intuitive experience for the user.

This research is limited to the personalization of loyal users, not to the interested parties of the independent luxury watch brands. While for marketing purposes, most insight collected from a brand's website typically is obtained from e-commerce, the independent luxury watch brands are currently limited to UX to measure the movement and interests of the users. The practical application of utilizing untapped 
'dark data' through the process of deep learning personalizes the interface and further utilizing AI technology to offer unique immersive experiences raises the innovation of personalization. The behavioral insights provided by deep learning can contextualize actionable information, which can then be applied by the brand's marketing management, retail managers, digital marketing, and public relations (PR) teams.

\section{Collection Process \& Insight}

1. Discovery of Audience Clusters based on Interests

2. Selection Process of Interest-Sets

3. Profiling / Persona of Audience

4. Discovery patterns from AI's Subset of Deep Learning

5. Select Deliverables That Align with Brand Through Mobile Applications

Further investigation and re-evaluation of changing audience should be measured through the new applied data collected from discovering of new AI subset of deep learning from the luxury consumer. The AI movement will continue to change the next generation of affluent consumer's expectations, and with a continued reliance on smartphone technology it is inevitable that the future of personalization will require further investigation. While we have specifically focused on these three independent luxury watchmakers and the four clusters of interests currently available on their websites, future research will need to more deeply examine how the continued evolution of deep learning measurements can be best utilized to match the organic interests of the next generation of loyal customers. The behavioral insights provided by deep learning can contextualize actionable information, which can then be applied throughout the luxury brand communication; marketing management, retail managers, digital marketing, and public relations (PR) teams.

\section{Conclusion}

In this paper, we aimed to revisit luxury customer's expectation in the digital age and discuss how the industry is in the midst of a revolution that is changing the level of expectations of personalization. There is no doubt that the new technology is shifting the levels of customization through interactive systems and personalized interface will continue to advance. The next generation of affluent consumers have a high demand for interactive visual content, and dynamic marketing capabilities concept helps to integrate data for creating the new value and competitive advantage for the company. Cognitive computing insight will continue to enable luxury Swiss watches makers to understand how to personalize for the next generation of affluent consumers; more research is required to continue to explore more actionable insight.

Keywords: digital marketing, artificial intelligence, dark data, millennial customers, dgeagnostic, big data, social media, and contextualized data

\section{References}

Anderson, M.K. 2017. Hubspot "Facebook Bots 101: What They Are, Who's Using Them \& What You Should Do About It". https://blog.hubspot.com/marketing/facebook-bots-guide).

Abbott, Lawrence (1955), Quality and Competition. New York: Columbia University Press. 
Barrales-Molina, V., Martínez-López, F. J. and Gázquez-Abad, J. C. (2014), Dynamic Marketing Capabilities: Toward an Integrative Framework. International Journal of Management Reviews, 16: 397-416

Barney J. B. (2010), Gaining and Sustaining Competitive Advantage, 4th Edition, Pearson Education.

Bashutkina M. (2016a) Building strong luxury brand in Swiss luxury watchmaking industry. Global Marketing Conference in Hong Kong - Conference proceedings.

Bruni D. and Verona (2009), Dynamic Marketing Capabilities in science-based firms: an exploratory investigation of the pharmaceutical industry. British Journal of Management Vol 20, pp. 101-117.

Day G. (1994), The capabilities of market-driven organizations. Journal of Marketing,, Vol 58, pp. 37-52.

Fang E. and Zou S. (2009), Antecedents and consequences of marketing dynamic capabilities in international joint ventures, Journal of International Business Studies, Vol 40, pp. 742-761.

Jones, T. M. 2017. IBM. "A beginner's guide to artificial intelligence, machine learning, and cognitive computing." Available at https://www.ibm.com/developerworks/library/cc-beginner-guide-machinelearning-ai-cognitive/index.htm

Kozlenkova I., Samaha S. and Palmatier R. (2013), Resource-Based Theory in Marketing, Journal of the Academy of Marketing Science, 41, January, pp.1-21.

Miller, C. February 24, 2016. Quibit. "Keep track of the small details"- A conversation with Vishal Katelia, MR PORTER. http://blog.qubit.com/conversation-mr-porter-part-2

Deep Learning, n/a. "Introduction to Deep Neural Networks". https://deeplearning4j.org/neuralnet-overview.

Noyes, K. March 3, 2016.Computer World IDG News. "5 things you need to know about A.I.: Cognitive, neural and deep, oh my!" https://www.computerworld.com/article/3040563/enterprise-applications/5things-you-need-to-know-about-ai-cognitive-neural-and-deep-oh-my.html

Schatsky D., Muraskin, Ragu Gurumurthy, R. 2015 https://dupress.deloitte.com/dupus-en/deloitte-review/issue-16/cognitive-technologies-businessapplications.html

Srivastava R., Faheyb L. and Christensen H. (2001), The resource-based view and marketing: The role of market-based assets in gaining competitive advantage, Journal of Management, Vol 27, pp. 777-802. 